6. Liu Y, Yan LM, Wan L, et al. Viral dynamics in mild and severe cases of COVID-19. The Lancet Infectious diseases 2020 March 19 [Epub ahead of print]. doi: 10.1016/S1473-3099(20)30232-2.
7. Zhu W, Wang Y, Xiao K, et al. Establishing and managing a temporary coronavirus disease 2019 specialty hospital in Wuhan, China. Anesthesiology 2020 March 19 [Epub ahead of print]. doi: 10.1097/ALN.0000000000003299.

\title{
Diagnostic options for coronavirus disease 2019 (COVID-19)
}

\author{
Yuanyuan Xiao $\mathrm{MM}^{1}$ (10), Zhong Peng $\mathrm{MD}^{2}$, Caixia Tan $\mathrm{MM}^{1}$, Xiujuan Meng $\mathrm{MD}^{1}$, Xun Huang $\mathrm{MD}^{1,3}$, Anhua $\mathrm{Wu}^{1,3}$ and \\ Chunhui Li MD ${ }^{1,3}$ (D) \\ ${ }^{1}$ Xiangya Hospital Central South University, Changsha, Hunan Province, China, ${ }^{2}$ State Key Laboratory of Agricultural Microbiology, College of Veterinary Medicine, \\ Huazhong Agricultural University, Wuhan 430070, Hubei, China and ${ }^{3}$ National Clinical Research Center for Geriatric Disorders (Xiangya Hospital), Changsha, \\ Hunan Province, China
}

To the Editor-The COVID-19 pandemic is posing a great challenge to global health and economy. Early accurate diagnosis plays a key role in fighting the disease. However, the diagnosis might be missed because of false-negative tests due to the insufficient sensitivity of the only test that detects SARS-CoV-2 or coinfection with other viruses. These false-negative results will affect clinical management decisions as well as control of the epidemic. Therefore, broader viral tests should be given to patients suspected to have COVID-19. Here, we discuss the existing methods of diagnosing COVID-19.

\section{Nucleic acid amplification tests (NAAT)}

The current first choice for the etiological diagnosis of COVID-19 is based on detection of unique sequences of virus RNA by real-time reverse-transcription polymerase chain reaction (rRT-PCR). ${ }^{1}$ The PCR test is appropriate for the acute phase of illness; however, cases of missed diagnoses have already been reported using this method. ${ }^{2,3}$ Recently, related research shows that the COVID-19-RdRp/Hel rRT-PCR test is highly sensitive and specific, which might help to reduce the false-negative rate and would be significantly useful for detecting specimens with low viral loads. ${ }^{3}$ Thus, in terms of technical and financial support, the current rRT-PCR testing available is relatively optimal for SARS-CoV-2 screening of suspected cases.

\section{Viral sequencing}

The application of next-generation sequencing may be an accurate diagnosis method for SARS-CoV-2, including metagenomics, hybrid capture-based sequencing, and amplicon-based next-generation sequencing. ${ }^{1,45}$ These 3 approaches show a higher sensitivity than conventional RT-PCR, and they can meet the need for secondary detection, diagnosis confirmation, and large-scale detection of RT-PCR false-negative results. ${ }^{5}$ However, high cost is currently an important obstacle to more widespread use of virus sequencing.

\section{Serological testing}

For patients with COVID-19, detectable SARS-CoV-2 antibodies are mainly divided into IgM and IgG. In general, most of SARS-CoV-2-specific IgM antibodies can be detected 3-5 days after

\footnotetext{
Authors for correspondence: Chunhui Li, Email: lichunhui@csu.edu.cn. Or Anhua Wu, Email: xywuanhua@csu.edu.cn

Cite this article: Xiao Y, et al. (2020). Diagnostic options for coronavirus disease 2019 (COVID-19). Infection Control \& Hospital Epidemiology, 41: 1358-1359, https://doi.org/ 10.1017/ice.2020.168
}

onset, and during the recovery period, IgG antibody titers are $\geq 4$ times higher than in the acute phase. ${ }^{4,6}$ An antibody test is appropriate for the convalescence phase of COVID-19 in case of a symptomatic infection. This method, however, is susceptible to the presence of some interfering substances in the blood sample (eg, rheumatoid factor, nonspecific IgM, etc), and therefore, it has a very high false-positive rate. Hence, SARS-CoV-2-specific IgM or IgG antibody testing can be used as a diagnostic standard for COVID-19 in the case of a negative NAAT, when 2 dynamic tests are required. ${ }^{1,6}$

\section{Rapid antigen tests}

In theory, rapid antigen tests have the advantages of fast detection speed and low cost, but as yet they have poor sensitivity and specificity for detecting coronaviruses (except MERS). ${ }^{7}$ Moreover, it is almost impossible to identify patients in the incubation period of infection, which is to say that antigen tests cannot be used as the sole basis for the diagnosis or exclusion of COVID-19. A pre-peerreviewed article reported that a fluorescence immunochromatographic assay is an accurate, rapid, early and simple method for detecting the nucleocapsid protein of SARS-CoV-2 in nasopharyngeal swab samples and urine samples for the diagnosis of COVID-19. ${ }^{8}$ This claim requires further investigation.

\section{Imaging examinations}

Because lung abnormalities may appear ahead of clinical manifestations and positive NAAT, some studies have recommended that early chest computerized tomography (CT) be used to screen suspected cases of COVID-19., 2,9,10 Furthermore, pneumonia manifests with chest CT imaging and suggests the evolution and prognosis of COVID-19. ${ }^{2,10}$ Nevertheless, due to the highly contagious nature of SARS-CoV-2 and the risk of transporting critically ill patients, the choice to conduct a chest CT scan in patients with suspected or established COVID-19 is made infrequently. In addition, lung ultrasonography may have great utility in managing COVID-19 pneumonia due to its safety, repeatability, absence of radiation, low cost, and point-ofcare use. ${ }^{9}$ For cases in which pulmonary ultrasound is not sufficient to answer clinical questions, a chest CT is needed.

In summary, combining assessment of imaging features with clinical and laboratory findings could facilitate early diagnosis of COVID-19. Here, we have systematically summarized the various diagnostic methods for SARS-CoV-2. More importantly, this work offers practical options for diagnosing COVID-19. Our experience

(C) 2020 by The Society for Healthcare Epidemiology of America. All rights reserved. This is an Open Access article, distributed under the terms of the Creative Commons Attribution licence (http://creativecommons.org/licenses/by/4.0/), which permits unrestricted re-use, distribution, and reproduction in any medium, provided the original work is properly cited. 
may help clinicians make better decisions in the effort to become victorious over SARS-CoV-2.

\section{Acknowledgments. None.}

Financial support. This work was supported by the Research Fund of Emergency Project of Prevention and Control for COVID-19 of Central South University (grant no. 160260003).

Conflicts of interest. All authors report no conflicts of interest related to this work.

\section{References}

1. Laboratory testing for coronavirus disease 2019 (COVID-19) in suspected human cases. World Health Organization website. https://www.who.int/ publications-detail/laboratory-testing-for-2019-novel-coronavirus-in-suspectedhuman-cases-20200117. Published 2020. Accessed April 8, 2020.

2. Shi $\mathrm{H}$, Han $\mathrm{X}$, Jiang $\mathrm{N}$, et al. Radiological findings from 81 patients with COVID-19 pneumonia in Wuhan, China: a descriptive study. Lancet Infect Dis 2020;20:425-434.

3. Chan JF, Yip CC, To KK, et al. Improved molecular diagnosis of COVID-19 by the novel, highly sensitive and specific COVID-19-RdRp/Hel real-time reverse transcription-polymerase chain reaction assay validated and with clinical specimens. J Clin Microbiol 2020 Mar 4 [Epub ahead of print]. doi: 10.1128/JCM.00310-20.

4. The diagnosical and therapeutic scheme for COVID-19 (trial version 7). National Health Commission of the Peoples Republic of China website. http://www.nhc.gov.cn/xcs/zhengcwj/202003/46c9294a7dfe4cef80dc7f 5912eb1989.shtml. Published 2020. Accessed April 8, 2020.

5. Xiao MF, Liu XQ, Ji JK, et al. Multiple approaches for massively parallel sequencing of HCoV-19 genomes directly from clinical samples. bioRxiv 2020. doi: $10.1101 / 2020.03 .16 .993584$

6. Zhao J,Yuan Q,Wang $\mathrm{H}$, et al. Antibody responses to SARS-CoV-2 in patients of novel coronavirus disease 2019. Clin Infect Dis 2020 [Epub ahead of print]. doi: 10.1093/cid/ciaa344.

7. Chen $\mathrm{Y}$, Chan $\mathrm{KH}$, Hong $\mathrm{C}$, et al. A highly specific rapid antigen detection assay for on-site diagnosis of MERS. J Infect 2016;73:82-84.

8. Diao B, Wen K, Chen J, et al. Diagnosis of acute respiratory syndrome coronavirus 2 infection by detection of nucleocapsid protein. medRxiv 2020. doi: $10.1101 / 2020.03 .07 .20032524$.

9. Xu X, Yu C, Qu J, et al. Imaging and clinical features of patients with 2019 novel coronavirus SARS-CoV-2. Eur J Nucl Med Mol Imaging 2020;47:1275-1280.

10. Peng QY, Wang XT, Zhang LN. Findings of lung ultrasonography of novel corona virus pneumonia during the 2019-2020 epidemic. Intensive Care Med 2020 Mar 12 [Epub ahead of print]. doi: 10.1007/s00134-020-05996-6.

\title{
Iran's success in controlling the COVID-19 pandemic
}

\author{
Nima Mohammadzadeh $\mathrm{PhD}^{1,2}$ (1), Mahla Shahriary $\mathrm{PhD}^{3}$ and Erfan Nasri MSc ${ }^{4}$ \\ ${ }^{1}$ Department of Microbiology, Faculty of Science, Shahid Beheshti University, Tehran, Iran, ${ }^{2}$ Student Research Committee, Iran University of Medical Sciences, \\ Tehran, Iran, ${ }^{3}$ Department of Microbiology, Tarbiat Modares University of Medical Sciences, Tehran, Iran and ${ }^{4}$ Student Research Committee, School of Medicine, \\ Guilan University of Medical Sciences, Rasht, Iran
}

To the Editor-Coronavirus disease 2019 (COVID-19) is a respiratory tract infection ranging from mild respiratory illness (eg, respiratory symptoms, cough, fever, shortness of breath and breathing difficulties) to severe illness (eg, pneumonia, severe acute respiratory syndrome, kidney failure, and death $)^{1}$ that has caused an unprecedented global crises in $<90$ days in all 206 countries of the world. ${ }^{2}$ Today, most of the world's major cities are in full quarantine and all social and economic behaviors have been limited due to the SARS-Cov-2 outbreak. Controlling the spread of the virus has become one of the most important challenges for governments across the globe. The increase in COVID-19 cases in the advanced industrial countries, including Italy, Germany, France, Spain, and United States, reflects the rapid spread of the virus. As of April 4, 2020, the following countries have been most affected: Italy, with a populations of almost 60 million, has $~ 119,827$ COVID-19 patients (case fatality rate [CFR], 12.25\%). Germany, with a population of almost 82 million, has $~ 85,778$ COVID-19 patients (CFR, 1.34\%). France, with a population of almost 66 million, has $\sim 63,536$ COVID-19 patients (CFR, 10.21\%). Spain, with a population of almost 46 million, has $\sim 117,710$ patients (CFR, 9.28\%). And the United States, with a population of 320 million, has $\sim 241,703$ patients (CFR, 2.42\%). The prevalence of SARS-CoV-2 is rapidly increasing.

Author for correspondence: Nima Mohammadzadeh, E-mail: nima.mz1111@gmail. com or mohammadzadeh.n@iums.ac.ir.

Cite this article: Mohammadzadeh N, Shahriary M, and Nasri E. (2020). Iran's success in controlling the COVID-19 pandemic. Infection Control \& Hospital Epidemiology, 41: 1359-1360, https://doi.org/10.1017/ice.2020.169
Iran, with a population of almost 81 million, has $~ 44,605$ COVID-19 patients, with 2,898 deaths (Fig. 1). Although Iran has been heavily sanctioned in all fields of industry and pharmacy, it has taken important steps from the earliest days of the outbreak to combat the virus. ${ }^{3}$

For example, Italy, with an outbreak date similar to that of Iran, has more than twice the disease incidence rate of Iran. According to reports released by the ministries of health in Iran and Italy, ${ }^{4,5}$ Iran formed a headquarters for the COVID-19 crisis on February 23, when the virus count was $\sim 15$ people per day. In contrast, in Italy, the COVID-19 crisis headquarters was formed on March 13, when the outbreak count was $\sim 2,500$ per day. Also, these countries' respective health ministries published safety and prevention guidelines for many locations, especially crowded centers including hospitals, clubs, transportation systems, schools, etc, in the early days of the outbreak. They also sought widespread collaboration with NGOs and volunteers as well as extensive intragovernmental collaboration to ensure the observation of safety protocols to control the spread of disease. Although traffic and concentration laws as well as heavy fines were not considered in the early days, these collaborations ultimately resulted in an $80 \%$ reduction in traffic between cities and as well as in social gatherings and even family gatherings. Ultimately, all of these measures have led Iran to better control the spread of the virus than other aforementioned industrialized countries. Nevertheless, Iran has a long way to go to achieve complete control of the pandemic.

Because Iran is located among neighboring countries in a very high-risk area for many diseases, including tuberculosis, rabies, Crimean Congo fever, cholera, brucella, malaria, polio, and some others, it has been even more successful in controlling such 